\title{
Adsorption of diuron and dichlobenil on multiwalled carbon nanotubes as affected by lead
}

\author{
Guang-Cai Chen a,b, Xiao-Quan Shan ${ }^{\mathrm{b}, *}$, Zhi-Guo Pei $^{\mathrm{b}}$, Huanhua Wang ${ }^{\mathrm{b}}$, \\ Li-Rong Zheng ${ }^{\mathrm{c}}$, Jing Zhang ${ }^{\mathrm{c}}$, Ya-Ning Xie ${ }^{\mathrm{c}}$ \\ a Research Institute of Subtropical Forestry, Chinese Academy of Forestry, Fuyang, Zhejiang 311400, China \\ b State Key Laboratory of Environmental Chemistry and Ecotoxicology, Research Center for Eco-Environmental Sciences, Chinese Academy of Sciences, Beijing 100085, China \\ ${ }^{\mathrm{c}}$ Beijing Synchrotron Radiation Laboratory, Institute of High Energy Physics, Chinese Academy of Sciences, Beijing 100049, China
}

\section{A R T I C L E I N F O}

\section{Article history:}

Received 15 September 2010

Received in revised form 19 January 2011

Accepted 21 January 2011

Available online 31 January 2011

\section{Keywords:}

Diuron

Dichlobenil

Lead

Carbon nanotubes

Adsorption

\begin{abstract}
A B S T R A C T
The effect of lead on the adsorption of diuron and dichlobenil on multiwalled carbon nanotubes (MWCNTs) was investigated to explore the possible application of MWCNTs for removal of both herbicides from contaminated water. The adsorption of diuron and dichlobenil on MWCNTs at pH 6 was nonlinear and fit the Polanyi-Manes model well. The adsorption of diuron and dichlobenil was closely correlated with specific surface areas and micropore volumes of MWCNTs. An increase in oxygen content of MWCNTs with same diameters and similar surface areas decreased the adsorption of diuron and dichlobenil, while increased the adsorption of lead. Micro-Fourier transform infrared spectroscopic study indicated that hydrogen bonding is a main mechanism responsible for the adsorption of diuron or dichlobenil onto MWCNTs-O. Oxygen containing groups, mainly carboxylic groups, significantly increased the adsorption of lead through the formations of outer-sphere and inner-sphere complexes, which are verified by X-ray absorption spectroscopic measurements. Oxygen containing groups and the presence of lead diminished the adsorption of diuron and dichlobenil. The suppression mechanisms of lead were ascribed to hydration and complexation of lead with carboxylic groups, which may occupy part of surface of MWCNTs-O. The large hydration shell of lead cations may intrude or shield hydrophobic and hydrophilic sites, resulting in a decreased adsorption of diuron and dichlobenil at the lead-complexed moieties.
\end{abstract}

(C) 2011 Elsevier B.V. All rights reserved.

\section{Introduction}

Diuron is a non-selective herbicide and mainly used for both preemergent and post-emergent weed control on broadleaf and grassy weeds along with mosses and algae on crop or non-crop sites [1]. Dichlobenil is used to kill unwanted weeds and is remarkably persistant in soil [2]. Diuron and dichlobenil are frequently detected in ground and surface waters due to their worldwide use, relatively high chemical stability in soils and aquifers, and high leaching potential [3-5]. Lead is common detected metal in natural waters and soils due to discharge of industrial processes and sewage irrigation [6]. There has been increasing concern and more stringent regulation standards pertaining to the application of herbicide and discharge of heavy metals to the aquatic environment [7]. Hence, simultaneous removal of these toxic contaminants from wastewa-

\footnotetext{
* Corresponding author at: State Key Laboratory of Environmental Chemistry and Ecotoxicology, Research Center for Eco-Environmental Sciences, Chinese Academy of Sciences, Beijing 10085, China. Tel.: +86 10 62923560; fax: +86 1062923563.

E-mail address: xiaoquan@rcees.ac.cn (X.-Q. Shan).
}

ter is an important environmental issue. Adsorption has been found to be superior to other techniques for wastewater treatment due to its low-cost, high efficient and easy of operation.

Carbon nanotubes (CNTs) have been increasingly applied in the environmental protection as novel materials due to their strong adsorption affinity for both heavy metals and organic chemicals [8-15]. CNTs are considered a superior adsorbent for potential environmental remediation due to their large surface area and high reactivity [16-19]. The sorption mechanisms of organic chemicals by CNTs include hydrophobic interactions [20-23], $\pi-\pi$ interaction [24,25], hydrogen bond [26-28], electrostatic interactions and Lewis acid-base interaction [26,29]. However, the relative contribution of a given mechanism to the overall sorption is largely unclear, which needs to be further addressed.

Extensive researches suggested that CNTs have strong sorption affinity for heavy metals due to high chemisorption capability $[9,11,30]$. It was reported that CNTs show exceptional high adsorption efficiency for lead. The adsorption is significantly influenced by $\mathrm{pH}$ of solution and nanotube surface status, which can be controlled by their treatment processes [8]. Further research [30] suggested that oxygen functional groups play an important role 
in lead adsorption to form chemical complex adsorption, which accounts for $75.3 \%$ of all lead adsorption capacity [30].

To date, most current studies focus on the adsorption of single organic chemical(s) or heavy metal(s) by CNTs separately. However, the single-solute systems may not represent many systems commonly encountered in the environment, where multiple contaminants may coexist at many contaminated sites [31]. Previous studies suggested that metal cations may influence the environmental fate of toxic chemicals in soil-water systems [32,33]. Our primary study showed that metallic cations may influence the adsorption of atrazine and 2,4,6-trichlorophenol onto CNTs [28,34], implying that organic chemicals exhibit different environmental behaviors in multiple contaminant system from that in singlesolute systems.

The coexistence of diuron, dichlobenil and lead tend to influence their adsorption, transport and fate in the environment. However, question on the effects of lead on the adsorption of diuron and dichlobenil or vice versa by MWCNTs have not been addressed. The possible influence should be considered when CNTs were applied as adsorbents in waste water treatment. For these reasons a better understanding of interactions between diuron, dichlobenil and lead during their adsorption on CNTs is becoming an environmentally important issue.

The aims of this study were (i) to elucidate the effect of lead on the adsorption of diuron and dichlobenil on MWCNTs containing oxygen functional groups; and (ii) to provide an insight to the relevant mechanisms using Fourier transform infrared microspectroscopic ( $\mu$-FTIR) and X-ray absorption spectroscopic (XAS) studies.

\section{Materials and methods}

\subsection{Chemicals}

Diuron and dichlobenil were purchased from Sigma-Aldrich Chemical Co. with a reported purity of HPLC-Grade $97.4 \%$ and used as received. The selected physiochemical properties are listed in Table $1 . \mathrm{Pb}\left(\mathrm{NO}_{3}\right)_{2}$ is of guarantee reagent grade. Other chemicals are of analytical reagent grade or better.

\subsection{MWCNTS}

MWCNTs were purchased from Chengdu Organic Chemistry Co. Ltd., Chinese Academy of Sciences. These MWCNTs were synthesized from ethylene/nitrogen $\left(\mathrm{C}_{2} \mathrm{H}_{4} / \mathrm{N}_{2}=3 / 2\right)$ mixture by chemical vapor deposition at $823 \mathrm{~K}$ using $\mathrm{Fe} / \mathrm{Al}_{2} \mathrm{O}_{3}$ catalyst. MWCNTs with outer diameters of $<8 \mathrm{~nm}, 30-50 \mathrm{~nm}$ and $>50 \mathrm{~nm}$ were designated as MWCNTs8, MWCNTs30, MWCNTs50, respectively. According to the contained oxygen contents other MWCNTs with outer diameters of $10-20 \mathrm{~nm}$ were designated as MWCNTs-O(1.52\%), MWCNTs-O(2.66\%) and MWCNTs-O(7.58\%), respectively.

The diameters of MWCNTs were determined by TEM. The carbon and oxygen contents were determined by X-ray photoelectron spectroscopy (ESCALab220i-XL electron spectrometer from VG Sci-
Table 1

Properties of diuron and dichlobenil.

\begin{tabular}{|c|c|c|}
\hline Properties & Diuron & Dichlobenil \\
\hline Chemical formula & $\mathrm{C}_{9} \mathrm{H}_{10} \mathrm{Cl}_{2} \mathrm{~N}_{2} \mathrm{O}$ & $\mathrm{C}_{7} \mathrm{H}_{3} \mathrm{Cl}_{2} \mathrm{~N}$ \\
\hline Chemical structure & $\mathrm{NHCO}$ & \\
\hline Molecular weight (g/mol) & 233.09 & 172.02 \\
\hline Molecular volume $\left(\mathrm{cm}^{3} / \mathrm{mol}\right)$ & 170.1 & 122.4 \\
\hline Molecular surface area $\left(\mathrm{nm}^{2}\right)$ & 2.19 & 1.423 \\
\hline Density $\left(\mathrm{cm}^{3} / \mathrm{g}\right)$ & 1.1786 & 1.3 \\
\hline Dipolar moment (Debyes) & 7.55 & 5.54 \\
\hline Water solubility $\left(\mathrm{mg} \mathrm{L}^{-1}, 20^{\circ} \mathrm{C}\right)$ & 40 & 18 \\
\hline $\log K_{\mathrm{ow}}$ & 2.85 & 2.74 \\
\hline
\end{tabular}

entific) using 300W AlK $\alpha$ radiation under the base pressure of about $3 \times 10^{-9}$ mbar. The surface area, pore volume and micropore were measured by nitrogen gas adsorption and desorption at $77 \mathrm{~K}$ with ASAP2020 accelerated surface area and porosimetry systems (Micromeritics Instrument Corporation), and then calculated by multi-point BET, BJH, and DR methods. The structural properties of MWCNTs are shown in Table 2. Preliminary experiments indicated that impurities of $\mathrm{Pb}^{2+}$, diuron and dichlobenil in all MWCNTs were below the detection limits.

\subsection{Batch adsorption}

Briefly, $40 \mathrm{ml}$ of glass tube sealed with Teflon-lined screwcaps was used as batch reactors. $5 \mathrm{mg}$ of MWCNTs and $35 \mathrm{ml}$ of diuron/dichlobenil solution at various concentrations ( $\sim 0.6-22 \mathrm{mg} \mathrm{L}^{-1}$ of diuron and $\sim 0.6-13 \mathrm{mg} \mathrm{L}^{-1}$ of dichlobenil) were utilized for all adsorption experiments. A mixture of $0.01 \mathrm{M}$ $\mathrm{NaNO}_{3}$ and $0.1 \mathrm{~g} / \mathrm{L} \mathrm{NaN}_{3}$ was used as background solution. Reactors filled with MWCNTs and solutions were shaken at $100 \mathrm{rpm}$ and $20 \pm 0.5^{\circ} \mathrm{C}$ in a shaker (HZQ-F160) for $2 \mathrm{~d}$ at pH 6 (preliminary sorption studies indicated that apparent equilibration was reached $<2 \mathrm{~d}$ ). The $\mathrm{pH}$ of adsorbent suspension was adjusted to $6.0 \pm 0.1$ by drop wise addition of $0.1 \mathrm{M} \mathrm{HNO}_{3}$ or $0.1 \mathrm{M} \mathrm{NaOH}$ at the beginning of reaction and remained constantly at the end of the adsorption. After centrifugation at $2000 \times \mathrm{g}$ for $20 \mathrm{~min}$, all glass tubes were placed vertically to stand for $24 \mathrm{~h}$ to ensure complete separation of aqueous phase from MWCNTs at $20 \pm 0.5^{\circ} \mathrm{C}$ for diuron and dichlobenil. Supernatants were withdrawn and final concentrations of diuron and dichlobenil were determined by HPLC. After adsorption the suspension was filtered through a Millipore $0.25-\mu \mathrm{m}$ hydrophilic polyethersulfone membrane and final $\mathrm{Pb}^{2+}$ concentrations remained in the supernatant were determined using ICP-AES (Perkin-Elmer).

Experimental recoveries of batch equilibrium experiments were evaluated without MWCNTs. Total recovery of each adsorbate was $>97 \%$. Therefore, the adsorbed diuron, dichlobenil, and $\mathrm{Pb}^{2+}$ by MWCNTs were directly calculated by mass differences between their initial and final concentrations.

Table 2

Selected structural properties of MWCNTs.

\begin{tabular}{|c|c|c|c|c|c|c|c|c|}
\hline \multirow[t]{2}{*}{ MWCNTs } & \multirow[t]{2}{*}{ Outer diameter (nm) } & \multirow[t]{2}{*}{$\mathrm{C}(\%)$} & \multirow[t]{2}{*}{$\mathrm{O}$ (atom \%) } & \multicolumn{5}{|c|}{ Surface area $(\mathrm{SA})\left(\mathrm{m}^{2} \mathrm{~g}^{-1}\right)$} \\
\hline & & & & BET SA & $t$-Plot micro-pore SA & $t$-Plot external SA & $V_{\text {meso }}\left(\mathrm{cc} \mathrm{g}^{-1}\right)$ & $V_{\text {micro }}\left(\mathrm{cc} \mathrm{g}^{-1}\right)$ \\
\hline MWCNTs 8 & $<8$ & 97.9 & 2.1 & 558.15 & 67.33 & 490.81 & 1.62 & 0.117 \\
\hline MWCNTs30 & $30-50$ & 99.17 & 0.83 & 83.14 & 9.52 & 74.62 & 0.296 & 0.019 \\
\hline MWCNTs50 & $>50$ & 98.75 & 1.25 & 60.83 & 5.73 & 55.1 & 0.158 & 0.015 \\
\hline MWCNTs-O (1.52\%) & $10-20$ & 98.48 & 1.52 & 159.35 & 13.1 & 146.25 & 0.575 & 0.032 \\
\hline MWCNTs-O (2.66\%) & $10-20$ & 97.34 & 2.66 & 156.52 & 15.4 & 141.12 & 0.521 & 0.032 \\
\hline MWCNTs-O (7.58\%) & $10-20$ & 92.42 & 7.58 & 161.73 & 21.68 & 140.05 & 0.512 & 0.032 \\
\hline
\end{tabular}



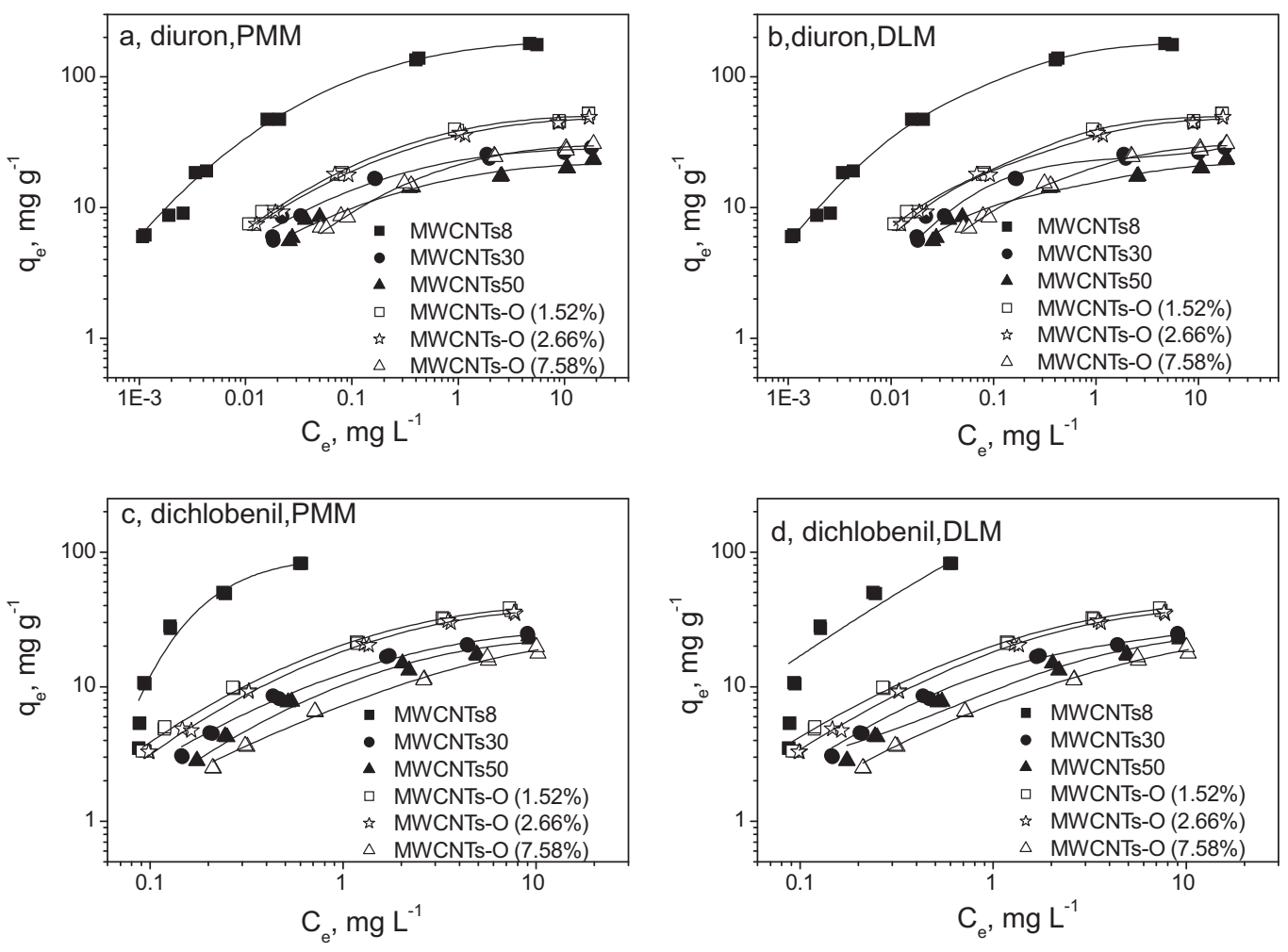

Fig. 1. Adsorption of diuron and dichlobenil on MWCNTs.

Table 3

Nonlinear sorption model

\begin{tabular}{|c|c|c|}
\hline Model & Equation & Capacity term ${ }^{\mathrm{a}}$ \\
\hline Polanyi-Manes & $q_{\mathrm{e}}=Q^{0} \operatorname{EXP}\left(a\left(\epsilon_{\mathrm{sw}} / V_{\mathrm{s}}\right)^{\mathrm{b}}\right) \epsilon_{\mathrm{sw}}=\mathrm{RT} \ln \left(C_{\mathrm{s}} / C_{\mathrm{e}}\right)$ & $\begin{array}{l}\epsilon_{\mathrm{sw}}[\mathrm{kJ} / \mathrm{mol}], \text { effective adsorption potential; } V_{\mathrm{s}}\left[\mathrm{cm}^{3} \mathrm{~mol}^{-1}\right] \text {, molar } \\
\text { volume of solute; } a\left[\left(\mathrm{~cm}^{3}\right)^{\mathrm{b}+1}(\mathrm{~kg} \mathrm{~J})^{-\mathrm{b}}\right] \text { and } \mathrm{b} \text {, fitting parameters; } R \\
{\left[8.314 \times 10^{-3} \mathrm{~kJ}(\mathrm{~mol} \mathrm{~K})^{-1}\right] \text {, universal gas constant; } T[\mathrm{~K}] \text {, absolute }} \\
\text { temperature potential }\end{array}$ \\
\hline Dual Langmuir & $q_{\mathrm{e}}=q_{\mathrm{m} 1} b_{1} C_{\mathrm{e}} /\left(1+b_{1} C_{\mathrm{e}}\right)+q_{\mathrm{m} 2} b_{2} C_{\mathrm{e}} /\left(1+b_{2} C_{\mathrm{e}}\right)$ & $\begin{array}{l}q_{\mathrm{m} 1}\left[\mathrm{mg} \mathrm{g}^{-1}\right] \text { and } q_{\mathrm{m} 2}\left[\mathrm{mg} \mathrm{g}^{-1}\right] \text {, sorbed capacity of site populations } 1 \\
\text { and } 2 \text {, respectively; } b_{1}\left[\mathrm{~L} \mathrm{mg}^{-1}\right] \text { and } b_{2}\left[\mathrm{~L} \mathrm{mg}^{-1}\right] \text {, affinity coefficient of } \\
\text { site populations } 1 \text { and } 2 \text {, respectively }\end{array}$ \\
\hline
\end{tabular}

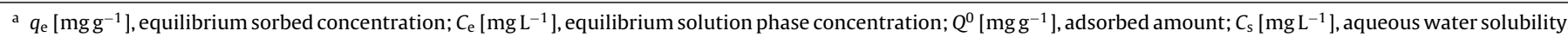

\subsection{Analyses of diuron and dichlobenil}

The concentrations of diuron and dichlobenil in equilibrium solutions were determined using a HPLC (Agilent Technologies 1200) equipped with a reversed-phase $C_{18}$ column $(5 \mu \mathrm{m}, 4.6 \mathrm{~mm} \times 200 \mathrm{~mm})$ and an UV-visible spectrophotometer (UV-visible HP $8452 \mathrm{~A}$ ) at $252 \mathrm{~nm}$ for diuron and $238 \mathrm{~nm}$ for dichlobenil. The mobile phase was acetonitrile/water (50/50, volume ratio) for diuron, and methanol/water (65/35, volume ratio) for dichlobenil, with a flow rate of $1.0 \mathrm{~mL} \mathrm{~min}^{-1}$. Detection limit of this method for diuron and dichlobenil was found to be $\sim 10 \mathrm{ppb}$.

\subsection{Fourier transform infrared micro-spectroscopic measurements}

Fourier transform infrared micro-spectroscopic ( $\mu$-FTIR) spectra were recorded on NICOLET iN 10 MX (Thermo Scientific). Samples for $\mu$-FTIR analysis were prepared with identical conditions to that used in the sorption experiments. MWCNTs, diuron- or dichlobenil-adsorbed MWCNTs were washed with above mentioned background solution and air-dried overnight. Microsamples were pressed on a diamond bracket and $\mu$-FTIR spectra

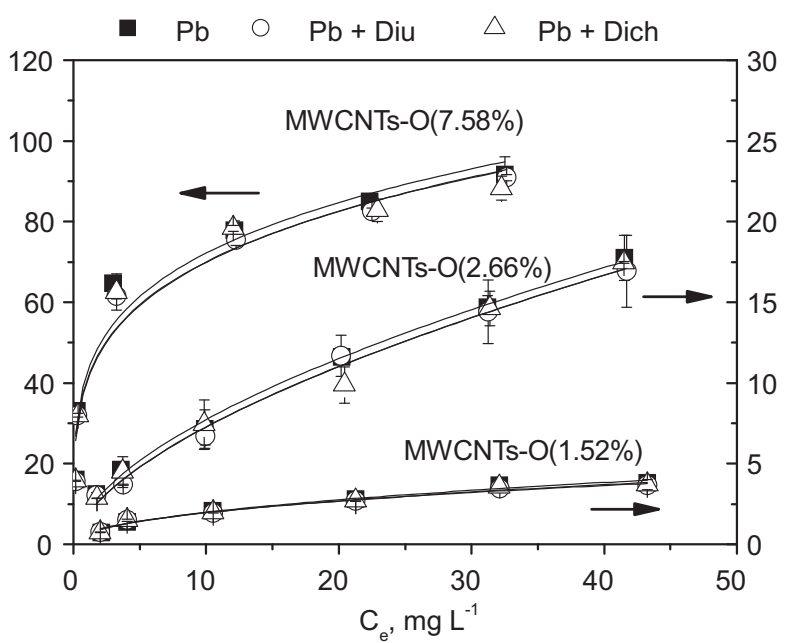

Fig. 2. Adsorption of lead to MWCNTs-O in the absence or presence of diuron or dichlobenil. 
Table 4

Results of Polanyi-Manes model fitting to the adsorption isotherms of diuron and dichlobenil on MWCNTs.

\begin{tabular}{|c|c|c|c|c|c|c|c|}
\hline MWCNTs & $Q^{0}$ & $a$ & $b$ & $Q_{\mathrm{SA}}\left(\mathrm{mg} \mathrm{m}^{-2}\right)$ & $\mathrm{SC}$ & MWSE & $R^{2}$ \\
\hline \multicolumn{8}{|l|}{ Diuron } \\
\hline MWCNTs8 & $182.72 \pm 2.32$ & $-964.89 \pm 237.31$ & $2.98 \pm 0.11$ & $0.33 \pm 0.03$ & $1.85 \pm 0.02^{\mathrm{a}}$ & $0.02^{\mathrm{b}}$ & 0.992 \\
\hline MWCNTs30 & $27.32 \pm 0.48$ & $-1181.51 \pm 830.09$ & $2.59 \pm 0.46$ & $0.34 \pm 0.01$ & $1.86 \pm 0.03^{a}$ & $0.009^{b}$ & 0.996 \\
\hline MWCNTs50 & $23.43 \pm 1.15$ & $-243.39 \pm 311.30$ & $2.34 \pm 0.55$ & $0.38 \pm 0.02$ & $2.18 \pm 0.11^{\mathrm{a}}$ & $0.006^{\mathrm{b}}$ & 0.986 \\
\hline MWCNTs-O(1.52\%) & $50.34 \pm 1.02$ & $-422.35 \pm 209.52$ & $2.51 \pm 0.22$ & $0.32 \pm 0.01$ & $1.79 \pm 0.04^{\mathrm{a}}$ & $0.01^{\mathrm{b}}$ & 0.974 \\
\hline MWCNTs-O(2.66\%) & $48.02 \pm 1.08$ & $-293.26 \pm 148.56$ & $2.34 \pm 0.22$ & $0.31 \pm 0.07$ & $1.74 \pm 0.04^{\mathrm{a}}$ & $0.002^{\mathrm{b}}$ & 0.996 \\
\hline MWCNTs-O(7.58\%) & $29.82 \pm 1.02$ & $-613.42 \pm 625.16$ & $2.55 \pm 0.41$ & $0.18 \pm 0.06$ & $1.04 \pm 0.03^{a}$ & $0.002^{\mathrm{b}}$ & 0.997 \\
\hline \multicolumn{8}{|l|}{ Dichlobenil } \\
\hline MWCNTs8 & $96.30 \pm 15.70$ & $-2.35 \mathrm{E} 6 \pm 1.90 \mathrm{E} 5$ & $6.15 \pm 3.49$ & $0.17 \pm 0.03$ & $0.86 \pm 0.14$ & 0.064 & 0986 \\
\hline MWCNTs30 & $24.60 \pm 0.65$ & $-340.78 \pm 166.78$ & $2.20 \pm 0.18$ & $0.30 \pm 0.01$ & $1.48 \pm 0.04$ & 0.002 & 0.997 \\
\hline MWCNTs50 & $22.15 \pm 3.35$ & $-152.92 \pm 94.71$ & $2.18 \pm 0.27$ & $0.36 \pm 0.06$ & $1.81 \pm 0.27$ & 0.009 & 0.988 \\
\hline MWCNTs-O(1.52\%) & $39.35 \pm 3.78$ & $-189.17 \pm 68.91$ & $2.31 \pm 0.17$ & $0.25 \pm 0.02$ & $1.23 \pm 0.12$ & 0.004 & 0.996 \\
\hline MWCNTs-O(2.66\%) & $37.16 \pm 3.76$ & $-116.76 \pm 21.66$ & $2.07 \pm 0.09$ & $0.24 \pm 0.02$ & $1.18 \pm 0.12$ & 0.002 & 0.995 \\
\hline MWCNTs-O(7.58\%) & $23.46 \pm 1.38$ & $-86.18 \pm 32.83$ & $1.60 \pm 0.23$ & $0.15 \pm 0.01$ & $0.72 \pm 0.05$ & 0.004 & 0.999 \\
\hline
\end{tabular}

Is surface coverage.

${ }^{b}$ MWSE is mean weighted square error, equal to $1 / v \sum\left[\left(q_{\text {measured }}-q_{\text {model }}\right)^{2} / q^{2}\right.$ measured $]$, where $v$ is the amount of freedom; $v=N-3$ for PMM, and $v=N-4$ for DLM.

were measured. FTIR spectra of MWCNTs are the average of 120 accumulated scans using a nominal resolution of $16 \mathrm{~cm}^{-1}$ due to very weak signals of MWCNTs, while spectra of pure diuron and dichlobenil are the average of 64 accumulated scans using a nominal resolution of $4 \mathrm{~cm}^{-1}$.

\subsection{X-ray absorption spectroscopic measurements and data analyses}

X-ray absorption spectroscopic (XAS) spectra at $\mathrm{Pb} \mathrm{L}_{\amalg}$-edge were obtained at 4W1B beamline of Beijing Synchrotron Radiation Facility using a Si (111) double crystal monochromator. Electron beam energy was $2.2 \mathrm{GeV}$ with a storage ring beam current of $80 \mathrm{~mA}$. Data analyses were performed using WinXAS2.1 following background correction and normalization, together with cubic spline, Fourier transformed, reverse Fourier transformed and EXAFS fittings. In the fitting procedure, the coordination number was fixed for the reference compounds, while the Debye-Waller factor was fixed for samples. Phase shifts and backscattering amplitudes were obtained from theoretical calculation using FEFF 7.0.

\section{Results and discussion}

\subsection{Characterization of MWCNTS}

Table 2 shows the selected structural properties of MWCNTs. Surface area and pore volume decreased in order of MWCNTs8 $>$ MWCNTs-O $(1.52 \%) \approx$ MWCNTs$\mathrm{O}(2.66 \%)>$ MWCNTs-O(7.58\%) > MWCNTs30> MWCNTs50. Among them, MWCNTs-O(1.52\%), MWCNTs-O(2.66\%) and MWCNTs$\mathrm{O}(7.58 \%)$ have different oxygen contents given in the parenthesis, but have same outer diameters and surface areas.

\subsection{Adsorption of diuron and dichlobenil}

Adsorption isotherms of diuron and dichlobenil on the MWCNTs are depicted in Fig. 1. Polanyi-Manes and Dual Langmuir models (Table 3) were applied to fit the adsorption data. The former fit all the adsorption isotherms well with the lowest MWSE (Table 4), and the later fit the adsorption isotherms well in most of cases with the exception of MWCNTs8 (data not shown). Hence the following discussion was only based on the adsorption parameters of Polanyi-Manes model fitting.

The results suggested that the adsorption of diuron and dichlobenil increased with increasing surface areas and pore volumes of MWCNTs. MWCNTs8 had the largest adsorption amount for both herbicides because MWCNTs8 has the largest surface area and pore volume. MWCNTs-O(1.52\%) and MWCNTs-O $(2.66 \%)$ have significantly larger $Q^{0}$ than that of MWCNTs-O(7.58\%), implying that an increase of oxygen content of MWCNTs decreased the adsorption due to deprotonation of carboxylic groups at $\mathrm{pH} 6$ [28], hence adsorption of water is more energetically favorable to the adsorption of diuron and dichlobenil.

The $Q_{S A}$ values were referred to as the normalized $Q^{0}$ by the surface areas of respective MWCNTs. Of $Q_{S A}$, MWCNTs50 has the largest $Q_{S A}$ for both diuron and dichlobenil, although MWCNTs50 has the lowest adsorbed amount of diuron and dichlobenil (Table 4$)$. We take $Q_{S A}$ of MWCNTs50 for diuron $\left(0.38 \mathrm{mg} \mathrm{m}^{-2}\right.$ )
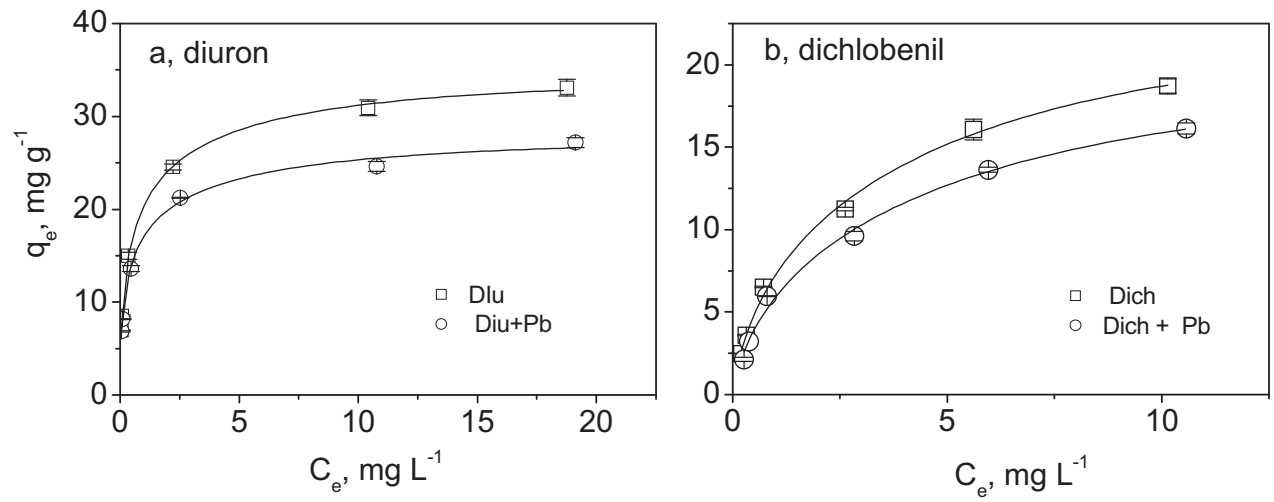

Fig. 3. Effects of lead on the adsorption of diuron and dichlobenil by MWCNTs-O(7.58\%). 
an example, which was larger than that of activated carbon $\left(0.36 \mathrm{mg} \mathrm{m}^{-2}\right)$, wheat carbon $\left(0.11 \mathrm{mg} \mathrm{m}^{-2}\right)$ and granular activated carbon $\left(0.27 \mathrm{mg} \mathrm{m}^{-2}\right)$, respectively, but smaller than that of activated carbon fiber $\left(0.39 \mathrm{mg} \mathrm{m}^{-2}\right)$ and activated carbon cloth $\left(0.41 \mathrm{mg} \mathrm{m}^{-2}\right)$, respectively $[35,36]$.

The values of $Q_{S A}$ and surface coverage (SC) of diuron are larger than that of dichlobenil, although the surface area, molecular volume and water solubility of dichlobenil are smaller. This discrepancy can partly be ascribed to greater van der Waals interactions for diuron than for dichlobenil due to the relatively larger dipolar moment [36]. These data show that the surface coverage of both herbicides is larger than 1 , suggesting that the adsorption of both on MWCNTs was multilayer.

Because MWCNTs-O(1.52\%), MWCNTs-O(2.66\%), and MWCNTs$\mathrm{O}(7.58 \%)$ have quite similar diameters and surface areas, but contain different oxygen contents, therefore we choose these MWCNTs to compare the effects of oxygen contents and lead on the adsorption of diuron and dichlobenil below.

\subsection{Adsorption of lead}

According to the speciation diagrams (Fig. A1), lead is mainly present as $\mathrm{Pb}^{2+}$ at $\mathrm{pH} 6$, which accounts for $98 \%$ of total lead and $\mathrm{PbOH}^{+}$accounts for $2 \%$. The adsorption isotherms of $\mathrm{Pb}^{2+}$ onto MWCNTs fit Freundlich equation well (Fig. 2). It is clearly indicated that the adsorption capacity of MWCNTs-O(1.52\%) is only $3.79 \mathrm{mg} \mathrm{g}^{-1}$ at an equilibrium concentration of $32.54 \mathrm{mg} \mathrm{L}^{-1}$ for $\mathrm{Pb}^{2+}$, while the adsorption capacities of MWCNTs-O(2.66\%) and MWCNTs-O(7.58\%) are $17.75 \mathrm{mg} \mathrm{g}^{-1}$ and $91.67 \mathrm{mg} \mathrm{g}^{-1}$ at the same equilibrium concentrations of $\mathrm{Pb}^{2+}$. These data implied that the surface $\mathrm{O}$-containing groups improved the ion-exchange capabilities of MWCNTs, and thus made $\mathrm{Pb}^{2+}$ adsorption increase accordingly. The underlying mechanisms of increased adsorption of lead by surface O-containing groups can be ascribed to "chemisorption" or chemicomplexation [11]. The dramatically increase of adsorption capacities of MWCNTs- $\mathrm{O}(7.58 \%)$ indicated that inner-sphere or outer-sphere complexes of $\mathrm{Pb}^{2+}$ are assumed to be formed on the surface of MWCNTs, which will be discussed in the XAS measurements.

It should be pointed out that the addition of $4 \mathrm{mg} \mathrm{L}^{-1}$ diuron or dichlobenil had little effect on the adsorption of $\mathrm{Pb}^{2+}$ for the tested MWCNTs (Fig. 2).

\subsection{Adsorption of diuron and dichlobenil as affected by lead}

To evaluate the effect of $\mathrm{Pb}^{2+}$ on the adsorption of diuron and dichlobenil, $50 \mathrm{mg} \mathrm{L}^{-1}$ of $\mathrm{Pb}^{2+}$ was simultaneously adsorbed with diuron and dichlobenil because this $\mathrm{Pb}$ concentration corresponds to the second level of Environmental Quality Standard for lead $\left(250 \mathrm{mg} \mathrm{kg}^{-1}\right)$ in Chinese soils if all $\mathrm{Pb}^{2+}$ were adsorbed.

The co-adsorption of $\mathrm{Pb}^{2+}$ with diuron or dichlobenil indicated that $\mathrm{Pb}^{2+}$ significantly suppressed the adsorption of diuron or dichlobenil on MWCNTs-O(7.58\%) (Fig. 3), and had little effect on the adsorption of herbicides onto MWCNTs-O(2.66\%) and MWCNTs-O(1.52\%) (Fig. A2). The $\mathrm{Pb}^{2+}$ suppression effect on the adsorption of diuron or dichlobenil was expressed as $\left(K_{\mathrm{d}}^{2}-K_{\mathrm{d}}^{1}\right) / K_{\mathrm{d}}{ }^{1}$, where $K_{\mathrm{d}}^{2}$, and $K_{\mathrm{d}}{ }^{1}$ represent the distribution coefficients of diuron or dichlobenil in the presence and absence of $\mathrm{Pb}^{2+}$, respectively. The presence of $\mathrm{Pb}^{2+}$ decreased diuron adsorption onto MWCNTs-O(7.58\%) by $\sim 10-30 \%$ and decreased dichlobenil sorption onto MWCNTs-O(7.58\%) by $\sim 15-30 \%$, respectively.

In order to explore the underlying mechanisms why $\mathrm{Pb}^{2+}$ suppressed the adsorption of diuron and dichlobenil we used $\mu$-FTIR and XAS study to provide an insight to the relevant mechanisms.

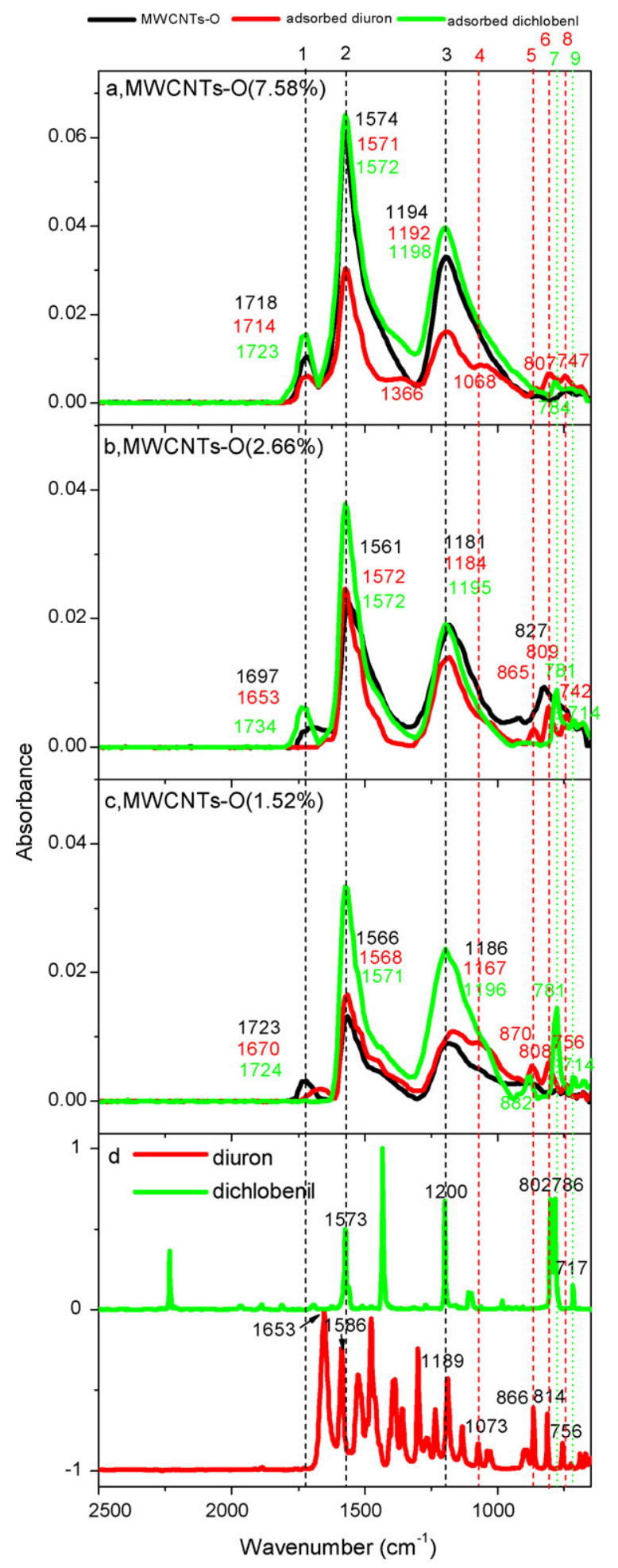

Fig. 4. $\mu$-FTIR spectra of MWCNTs-O(7.58\%) (a), MWCNTs- $\mathrm{O}(2.66 \%)$ (b), and MWCNTs-O(1.52\%) (c) without and with diuron or dichlobenil adsorbed, and pure diuron or dichlobenil (d).

\section{5. $\mu$-FTIR analysis}

To reveal the adsorption sites and verify the existence of hydrogen bonding of diuron and dichlobenil, a $\mu$-FTIR study was performed. The $\mu$-FTIR spectra of MWCNTs-O, diu-MWCNTs-O, and Dich-MWCNTs-O in the frequency range of $650-2500 \mathrm{~cm}^{-1}$ are shown in Fig. 4. As can be seen in Fig. 4a-c (black lines) the peaks at 

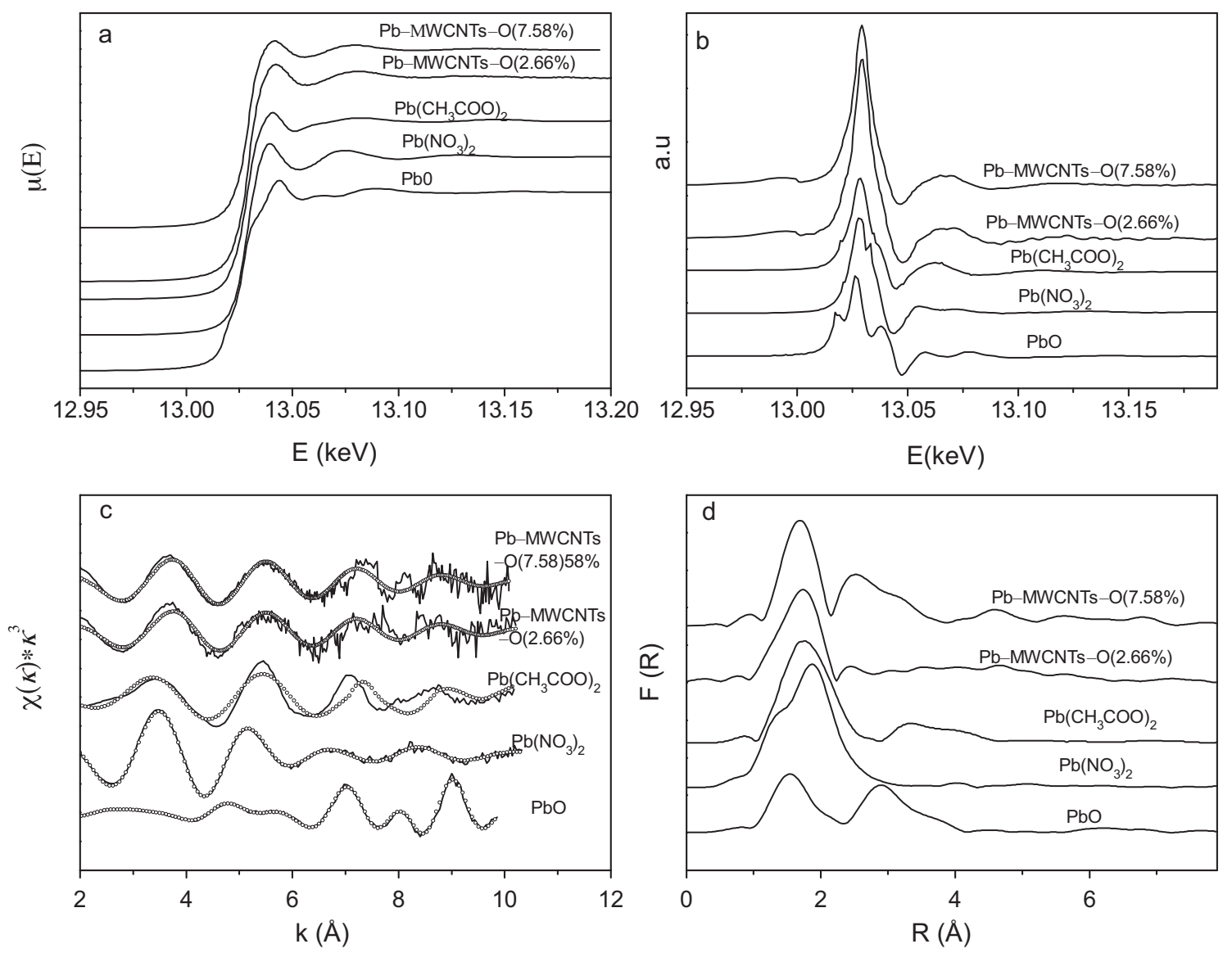

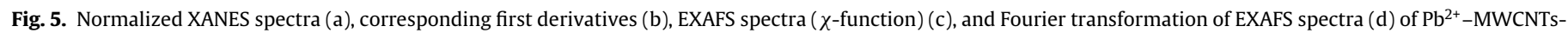
$\mathrm{O}(7.58 \%)$ and $\mathrm{Pb}^{2+}-\mathrm{MWCNTs}-\mathrm{O}(2.66 \%)$.

$\sim 1194 \mathrm{~cm}^{-1}$ can be assigned to $\mathrm{C}-\mathrm{O}$ stretching vibration [37], the peaks at $\sim 1574 \mathrm{~cm}^{-1}$ for -COO- to asymmetric stretching vibration of carboxylic bond $[11,18,38,39]$, the peaks at $\sim 1718 \mathrm{~cm}^{-1}$ to $\mathrm{C}=\mathrm{O}$ stretch of keto or carboxyl groups $[11,38]$.

For diuron (Fig. 4d, red line), the most intense bands were carbonyl peak at $\sim 1653 \mathrm{~cm}^{-1}$ and benzene ring stretching at $\sim 1525$, $\sim 1476$, and $\sim 1394 \mathrm{~cm}^{-1}$. Other absorption bands are located at $1586 \mathrm{~cm}^{-1}$ due to $\mathrm{C}=\mathrm{C}$ stretching vibration $[1,40]$, and $1189 \mathrm{~cm}^{-1}$ due to $\mathrm{C}-\mathrm{H}$ in-plane bending vibration of benzene ring, respectively. Peaks at $\sim 816, \sim 866$ and $\sim 756 \mathrm{~cm}^{-1}$ are assigned to mainly $\mathrm{C}-\mathrm{H}$ out-of plane bending vibration of benzene ring, and partly $\mathrm{C}-\mathrm{Cl}$ stretching vibration. For dichlobenil (Fig. 4d, green line), peak at $\sim 1573 \mathrm{~cm}^{-1}$ is assigned to $\mathrm{C}=\mathrm{C}$ stretching vibration, peak at $\sim 1433 \mathrm{~cm}^{-1}$ to benzene ring stretching, and $\sim 1200 \mathrm{~cm}^{-1}$ to inplane bending vibration of benzene ring, peaks at $\sim 802, \sim 786, \sim 717$ mainly to $\mathrm{C}-\mathrm{H}$ out-of plane bending vibration of benzene ring, and partly $\mathrm{C}-\mathrm{Cl}$ stretching vibration.

After diuron was adsorbed to MWCNTs-O(7.58\%), MWCNTs$\mathrm{O}(2.66 \%)$ and MWCNTs-O(1.52\%), new peaks appeared at $\sim 807 \mathrm{~cm}^{-1}, \sim 747 \mathrm{~cm}^{-1}$ (Fig. 4a, red line), $809 \mathrm{~cm}^{-1}, 742 \mathrm{~cm}^{-1}$ (Fig. 4b, red line) and $\sim 870 \mathrm{~cm}^{-1}, 808 \mathrm{~cm}^{-1}$ (Fig. 4c, red line), respectively, which were assigned to $\mathrm{C}-\mathrm{H}$ out-of plane bending vibration of benzene ring of diuron. The $\mathrm{C}-\mathrm{O}$ stretching vibration peaks at $\sim 1194 \mathrm{~cm}^{-1}$ (Fig. 4a, black line), $1181 \mathrm{~cm}^{-1}$ (Fig. 4 b, black line) and $1186 \mathrm{~cm}^{-1}$ (Fig. 4c, black line) $[1,40]$ were shifted to $\sim 1192 \mathrm{~cm}^{-1}$ (Fig. 4a, red line), $1184 \mathrm{~cm}^{-1}$ (Fig. 4b, red line) and $1167 \mathrm{~cm}^{-1}$ (Fig. 4c, red line), respectively, which can be assigned to $\mathrm{C}-\mathrm{H}$ in-plane bending vibration of benzene ring at $1189 \mathrm{~cm}^{-1}$ of diuron and the interaction between the $\mathrm{C}-\mathrm{O}$ and the benzene ring. The -COO- asymmetric stretching peaks at $\sim 1574 \mathrm{~cm}^{-1}$
(Fig. 4a, black line), $1561 \mathrm{~cm}^{-1}$ (Fig. 4b, black line), $1566 \mathrm{~cm}^{-1}$ (Fig. 4c, black line) $[1,40]$ were shifted to $1571 \mathrm{~cm}^{-1}$ (Fig. 4a, red line), $1572 \mathrm{~cm}^{-1}$ (Fig. 4b, red line) and $1568 \mathrm{~cm}^{-1}$ (Fig. 4c, red line), which were assigned to the $\mathrm{C}=\mathrm{C}$ stretching vibration at $1586 \mathrm{~cm}^{-1}$ of diuron and the interaction between the - $\mathrm{COO}$ - and the benzene ring. The $\mathrm{C}=0$ stretch peaks at $\sim 1718 \mathrm{~cm}^{-1}$ (Fig. 4a, black line), $1697 \mathrm{~cm}^{-1}$ (Fig. 4b, black line), $1723 \mathrm{~cm}^{-1}$ (Fig. 4c, black line) $[1,40]$ were shifted to $\sim 1714 \mathrm{~cm}^{-1}$ (Fig. $4 \mathrm{a}$, red line), $1653 \mathrm{~cm}^{-1}$ (Fig. $4 \mathrm{~b}$, red line), $1670 \mathrm{~cm}^{-11}$ (Fig. 4c, red line). These new appeared peaks and the band shifts on MWCNTs-O(7.58\%) suggested that diuron was partly adsorbed on surface of MWCNTs-O(7.58\%) by hydrogen bonding through the $\mathrm{C}=\mathrm{O}$, or $-\mathrm{COO}$ - groups.

After dichlobenil was adsorbed, new peaks at $\sim 784 \mathrm{~cm}^{-1}$ appeared on MWCNTs-O(7.58\%) (Fig. 4a, green lines), $\sim 784 \mathrm{~cm}^{-1}$, and $714 \mathrm{~cm}^{-1}$ on MWCNTs-O $(2.66 \%)$ (Fig. $4 \mathrm{~b}$, green lines), $882 \mathrm{~cm}^{-1}, 781 \mathrm{~cm}^{-1}$, and $714 \mathrm{~cm}^{-1}$ on MWCNTs-O(1.52\%) (Fig. 4c, green lines), which were assigned to $\mathrm{C}-\mathrm{H}$ out-of plane bending vibration of benzene ring of dichlobenil. The $\mathrm{C}-\mathrm{O}$ stretching vibration peaks at $\sim 1194 \mathrm{~cm}^{-1}$ (Fig. 4 a, black line), $1181 \mathrm{~cm}^{-1}$ (Fig. 4b, black line) and $1186 \mathrm{~cm}^{-1}$ (Fig. 4c, black line) were shifted to $1198 \mathrm{~cm}^{-1}$ (Fig. 4a, green line), $1196 \mathrm{~cm}^{-1}$ (Fig. $4 \mathrm{~b}$, green line), and $1196 \mathrm{~cm}^{-1}$ (Fig. 4c, green line) for MWCNTs$\mathrm{O}(7.58 \%)$, MWCNTs- $\mathrm{O}(2.66 \%)$ and MWCNTs-O $(1.52 \%)$, respectively, which were assigned to the in-plane bending vibration of benzene ring, at $1200 \mathrm{~cm}^{-1}$ of dichlobenil and the interaction between $\mathrm{C}-\mathrm{O}$ and benzene ring. The - $\mathrm{COO}-$ asymmetric stretching vibration peaks at $\sim 1574 \mathrm{~cm}^{-1}$ (Fig. 4a, black line), $1561 \mathrm{~cm}^{-1}$ (Fig. $4 \mathrm{~b}$, black line), $1566 \mathrm{~cm}^{-1}$ (Fig. 4c, black line) were shifted to $1572 \mathrm{~cm}^{-1}$ (Fig. 4a, green line), $1572 \mathrm{~cm}^{-1}$ (Fig. 4b, green line) and $1571 \mathrm{~cm}^{-1}$ (Fig. 4c, green line) for MWCNTs-O(7.58\%), MWCNTs-O $(2.66 \%)$ 
and MWCNTs- $\mathrm{O}(1.52 \%)$, respectively, which were assigned to $\mathrm{C}=\mathrm{C}$ stretching vibration at $1573 \mathrm{~cm}^{-1}$ and interaction of -COO- and benzene ring. The $\mathrm{C}=0$ stretch at $\sim 1718 \mathrm{~cm}^{-1}$ (Fig. $4 \mathrm{a}$, black line), $1697 \mathrm{~cm}^{-1}$ (Fig. 4b, black line), was shifted to $1723 \mathrm{~cm}^{-1}$ (Fig. 4a, green line), $1734 \mathrm{~cm}^{-1}$ (Fig. 4b, green line), for MWCNTs-O(7.58\%), and MWCNTs-O(2.66\%), respectively, which were assigned to interaction of dichlobenil and MWCNTs-O.

Considering the high electronegativity of $\mathrm{O}$ atom within $\mathrm{C}=\mathrm{O}$ groups and the presence of $\mathrm{H}$ atom from $\mathrm{O}-\mathrm{H}$ bond of MWCNTs, it was assumed that hydrogen bonding is the most probable reaction mode between diuron or dichlobenil with MWCNTs-O.

\subsection{XAS analysis}

XAS was used to identify the surface complexation and to obtain the coordination environment of $\mathrm{Pb}^{2+}$ adsorbed onto MWCNTs. Identification of such complex formation provides an insight into the suppression mechanism of diuron and dichlobenil adsorption by $\mathrm{Pb}^{2+}$.

$\mathrm{Pb} \mathrm{L}_{\amalg}$ XANES spectra are quite sensitive to local atomic structure of the first few neighbor atom shells [41]. Distinct differences in near-edge structure can facilitate discrimination between model compounds and adsorbed samples, in which $\mathrm{Pb}$ is coordinated in different environments. The XANES (Fig. 5a) of $\mathrm{Pb}^{2+}$ showed a distinct difference shoulder around $13.00-13.05 \mathrm{keV}$ and 13.05-13.10 keV region among $\mathrm{PbO}, \mathrm{Pb}\left(\mathrm{NO}_{3}\right)_{2}, \mathrm{~Pb}\left(\mathrm{CH}_{3} \mathrm{COO}\right)_{2}$, and $\mathrm{Pb}^{2+}-\mathrm{MWCNTs}-\mathrm{O}(7.58 \%)$ and $\mathrm{Pb}^{2+}-\mathrm{MWCNTs}-\mathrm{O}(2.66 \%)$. The similarities in XANES spectra between $\mathrm{Pb}^{2+}$-MWCNTs-O(7.58\%), $\mathrm{Pb}^{2+}$-MWCNTs- $\mathrm{O}(2.66 \%)$ and $\mathrm{Pb}\left(\mathrm{CH}_{3} \mathrm{COO}\right)_{2}$ suggested that the coordination environment of $\mathrm{Pb}$ in those compounds was similar. Roe et al. [42] proposed the presence of an intense peak at $\sim 40 \mathrm{eV}$ above the first sharp peak in the first derivative spectra of XANES for $\mathrm{Pb}$ as an indicator of outer-sphere complexation. However, there was no such feature at this energy level in the first derivative spectra of XANES for $\mathrm{Pb}^{2+}-\mathrm{MWCNTs}-\mathrm{O}$ (7.58\%) and $\mathrm{Pb}^{2+}$-MWCNTs-O(2.66\%) (Fig. 5b).

The $k^{3}$-weighted EXAFS spectra for $\mathrm{Pb}^{2+}-\mathrm{MWCNTs}-\mathrm{O}(7.58 \%)$ and $\mathrm{Cu}-\mathrm{MWCNTs}-\mathrm{O}(2.66 \%)$ and their corresponding radial structural functions (RSF) derived from Fourier transformation are presented in Fig. $5 \mathrm{c}$ and d. A good agreement was obtained between the spectra of $\mathrm{Pb}^{2+}-\mathrm{MWCNTs}-\mathrm{O}(7.58 \%)$ and $\mathrm{Pb}^{2+}-\mathrm{MWCNTs}-\mathrm{O}(2.66 \%)$ and that of $\mathrm{Pb}\left(\mathrm{CH}_{3} \mathrm{COO}\right)_{2}$ among the first three oscillations at 3.7, 5.6 and $7.1 \AA$, which constitute a good fingerprint of $\mathrm{Pb}\left(\mathrm{CH}_{3} \mathrm{COO}\right)_{2}$ (Fig. 5c), and indicate $\mathrm{Pb}^{2+}$ coordination on MWCNTs-O(7.58\%) and MWCNTs-O(2.66\%) through carboxylic moieties. Fig. 5d shows a broad peak centered at $\sim 1.7 \AA$ for $\mathrm{Pb}^{2+}-\mathrm{MWCNTs}-\mathrm{O}(7.58 \%)$, $\mathrm{Pb}^{2+}-\mathrm{MWCNTs}-\mathrm{O}(2.66 \%)$ and $\mathrm{Pb}\left(\mathrm{CH}_{3} \mathrm{COO}\right)_{2}$, which results from backscattering in the first coordination shell of $\mathrm{Pb}$ atoms. The fitting of this peak leads to 1.8 oxygen atoms at $2.38 \AA$ for $\mathrm{Pb}^{2+}-\mathrm{MWCNTs}-\mathrm{O}(7.58 \%)$ and 1.8 oxygen atoms at $2.37 \AA$ for $\mathrm{Pb}^{2+}-\mathrm{MWCNTs}-\mathrm{O}(2.66 \%)$. These results are similar to that of Dupont et al. [43]. The coordination number was particularly low as expected because of the highly structural disorder of $\mathrm{Pb}$ coordination shells. The $\mathrm{L}_{\amalg}$-edge XANES spectra (Fig. 5a), EXAFS functions (Fig. 5c) and corresponding radial structure function (Fig. 5d) appeared to be very similar for $\mathrm{Pb}^{2+}-\mathrm{MWCNTs}-\mathrm{O}(7.58 \%)$, $\mathrm{Pb}^{2+}-\mathrm{MWCNTs}-\mathrm{O}(2.66 \%)$ and $\mathrm{Pb}\left(\mathrm{CH}_{3} \mathrm{COO}\right)_{2}$, which indicated $\mathrm{Pb}$ coordination on MWCNTs-O(7.58\%) and MWCNTs-O(2.66\%) mostly through carboxylic moieties.

\section{Conclusion}

The adsorption of diuron and dichlobenil was closely correlated with surface areas and micropore volumes of MWCNTs. Of them, MWCNTs50 had the largest $Q_{\mathrm{SA}}$, although the adsorbed diuron and dichlobenil were lower, implying that MWCNTs50 had the highest adsorption capacity. An increase in the oxygen contents decreased the adsorption of diuron and dichlobenil, while increased the adsorption of lead for MWCNTs with outer diameter of 10-20 nm.

The presence of $\mathrm{Pb}^{2+}$ decreased the adsorption of diuron and dichlobenil. Two mechanisms may be involved. Complexation of $\mathrm{Pb}^{2+}$ with carboxylic groups and hydrated lead cation occupy part of surface of MWCNTs-O. The metal cation hydration shells may intrude or shield the hydrophobic and hydrophilic sites of MWCNTs, leading to the inhibition of adsorption of diuron and dichlobenil around the metal-complexed moieties.

\section{Acknowledgments}

This work was funded by the National Natural Science Foundation of China (grant number: 41071308). Dr. Weng Shifu, College of Chemistry and Molecular Engineering, Peking University, was highly appreciated for his constructive discussion on FTIR data.

\section{Appendix A. Supplementary data}

Supplementary data associated with this article can be found, in the online version, at doi:10.1016/j.jhazmat.2011.01.095.

\section{References}

[1] S. Armenta, G. Quintaas, A. Morales, S. Garrigues, M.D.L. Guardiaj, FTIR approaches for diuron determination in commercial pesticide formulations, J. Agric. Food. Chem. 53 (2005) 5842-5847.

[2] C. Cox, Herbicide factsheet: dichlobenil, J. Pestic. Reform. 17 (1997) 14-20.

[3] J.H. Montgomery, Agrochemicals Desk Reference, Lewis Publishers, Chelsea, MI 1993, p. 625.

[4] L. Clausen, F. Larsen, H.J. Albrechtsen, Sorption of the herbicide dichlobenil and the metabolote 26 -dichlorobenzamide on soils and aquifer sediments, Environ. Sci. Technol. 38 (2004) 4510-4518.

[5] A. Newman, Ranking pesticides by environmental impact, Environ. Sci. Technol. 29 (1995) 324A-326A.

[6] P. Li, X. Wang, G. Allinsonb, X. Li, X. Xiong, Risk assessment of heavy metals in soil previously irrigated with industrial wastewater in Shenyang, China, J. Hazard. Mater. 161 (2009) 516-521.

[7] P.W. Purdom, Environmental Health, Academic Press, New York, 1980.

[8] Y.H. Li, S. Wang, J. Wei, X. Zhang, Z. Luan, D. Wu, B. Wei, Lead adsorption on carbon nanotubes, Chem. Phys. Lett. 357 (2002) 263-266.

[9] Y.H. Li, J. Ding, Z.K. Luan, Z.C. Di, Y.F. Zhu, C.L. Xu, D.H. Wu, B.O. Wei, Competitive adsorption of $\mathrm{Pb}^{2+}, \mathrm{Cu}^{2+}$ and $\mathrm{Cd}^{2+}$ ions from aqueous solutions by multiwalled carbon nanotubes, Carbon 41 (2003) 2787-2792.

[10] Y.H. Li, Z. Di, J. Ding, D. Wu, Z. Luan, Y. Zhu, Adsorption thermodynamic, kinetic and desorption studies of $\mathrm{Pb}^{2+}$ on carbon nanotubes, Water Res. 39 (2005) 605-609.

[11] X.K. Wang, G. Chen, W. Hu, A. Ding, D. Xu, X. Zhou, Sorption of ${ }^{243}$ Am(III) to multiwall carbon nanotubes, Environ. Sci. Technol. 39 (2005) 2856-2860.

[12] J. Hu, C.L. Chen, X.X. Zhu, X.K. Wang, Removal of chromium from aqueous solution by using oxidized multiwalled carbon nanotubes, J. Hazard. Mater. 162 (2009) 1542-1550.

[13] R.Q. Long, R.T. Yang, Carbon nanotubes as superior sorbent for dioxin removal J. Am. Chem. Soc. 123 (2001) 2058-2059.

[14] C. Lu, Y.L. Chung, K.F. Chang, Adsorption of trihalomethanes from water with carbon nanotubes, Water Res. 39 (2005) 1183-1189.

[15] C.J.M. Chin, L.C. Shih, H.J. Tsai, T.K. Liu, Adsorption of o-xylene and p-xylene from water by SWCNTs, Carbon 45 (2007) 1254-1260.

[16] M.S. Mauter, M. Elimelech, Environmental applications of carbon-based nanomaterials, Environ. Sci. Technol. 42 (2008) 5843-5859.

[17] B. Fugetsu, S. Satoh, T. Shiba, T. Mizutani, Y. Lin, N. Terui, Y. Nodasaka, K. Sasa, K Shimizu, T. Akasaka, M. Shindoh, K. Shibata, A. Yokoyama, M. Mori, K. Tanaka, Y. Sato, K. Tohji, S. Tanaka, N. Nishi, F. Watari, Caged multiwalled carbon nanotubes as the adsorbents for affinity-based elimination of ionic dyes, Environ. Sci. Technol. 38 (2004) 6890-6896.

[18] X.M. Yan, B.Y. Shi, J.J. Lu, C.H. Feng, D.S. Wang, H.X. Tang, Adsorption and desorption of atrazine on carbon nanotubes, J. Colloid Interface Sci. 321 (2008) 30-38.

[19] K. Yang, L.Z. Zhu, B.S. Xing, Adsorption of polycyclic aromatic hydrocarbons by carbon nanomaterials, Environ. Sci. Technol. 40 (2006) 1855-1861.

[20] S. Gotovac, L. Song, H. Kanoh, K. Kaneko, Assenthly structure control of single wall carbon nanotubes with liquid phase naphthalene adsorption, Colloids Surf. A 300 (2007) 117-121.

[21] K. Pyrzynska, A. Stafiej, M. Biesaga, Sorption behavior of acidic herbicides on carbon nanotubes, Microchim. Acta 159 (2007) 293-298. 
[22] R.J. Chen, S. Bangsaruntip, K.A. Drouvalakis, N.W.S. Kam, M. Shim, Y.M. Li, W. Kim, P.J. Utz, H.J. Dai, Noncovalent functionalization of carbon nanotubes for highly specific electronic biosensors, Proc. Natl. Acad. Sci. U.S.A. 100 (2003) 4984-4989.

[23] F. Balavoine, P. Schultz, C. Richard, V. Mallouh, T.W. Ebbesen, C. Mioskowski, Helical crystallization of proteins on carbon nanotubes: a first step towards the development of new biosensors, Angew. Chem. Int. Ed. 38 (1999) 1912-1915

[24] J. Zhang, J.K. Lee, Y. Wu, R.W. Murray, Photoluminescene and electronic interaction of anthracene derivatives adsorbed on sidewalls of single-walled carbon nanotubes, Nano Lett. 3 (2003) 403-407.

[25] W. Chen, L. Duan, D.Q. Zhu, Adsorption of polar and nonpolar organic chemicals to carbon nanotubes, Environ. Sci. Technol. 41 (2007) 8295-8300.

[26] W. Chen, L. Duan, L. Wang, D.Q. Zhu, Adsorption of hydroxyl and aminosubstituted aromatics to carbon nanotubes, Environ. Sci. Technol. 42 (2008) 6862-6868.

[27] D.H. Lin, B.S. Xing, Adsorption of phenolic compounds by carbon nanotubes: role of aromaticity and substitution of hydroxyl groups, Environ. Sci. Technol. 42 (2008) 7254-7259.

[28] G.C. Chen, X.Q. Shan, Y.S. Wang, Z.G. Pei, X.E. Shen, B. Wen, G. Owens, Effects of copper, lead, and cadmium on the sorption and desorption of atrazine onto and from carbon nanotubes, Environ. Sci. Technol. 42 (2008) 8297-8302.

[29] B. Pan, D. Lin, H. Mashayekhi, B.S. Xing, Adsorption and hysteresis of bisphenol A and 17a-ethinyl estradiol on carbon nanomaterials, Environ. Sci. Technol. 42 (2008) 5280-5485.

[30] H.J. Wang, A.L. Zhou, F. Peng, H. Yu, J. Yang, Mechanism study on adsorption of acidified multiwalled carbon nanotubes to $\mathrm{Pb}(\mathrm{II})$, J. Colloid Interface Sci. 316 (2007) 277-283.

[31] J.Y. Dai, M.Q. Xu, J.P. Chen, X.P. Yang, Z.S. Ke, PCDD/F, PAH and heavy metals in the sewage sludge from six wastewater treatment plants in Beijing, China, Chemosphere 66 (2007) 353-361.

[32] S. Dousset, A.R. Jacobson, J.B. Dessogne, N. Guichard, P.C. Baveye, F. Andreux, Facilitated transport of diuron and glyphosate in high copper vineyard soils, Environ. Sci. Technol. 41 (2007) 8056-8061.
[33] Z.G. Pei, X.Q. Shan, B. Wen, B. He, T. Liu, Y.N. Xie, G. Owens, Sorption of anionic metsulfuron-methyl and cationic difenzoquat on peat and soil as affected by copper, Environ. Sci. Technol. 42 (2008) 6849-6854.

[34] G.C. Chen, X.Q. Shan, Y.S. Wang, B. Wen, Z.G. Pei, Y.N. Xie, T. Liu, J.J. Pignatello, Adsorption of 24,6 -trichlorophenol onto multi-walled carbon nanotubes as affected by Cu (II), Water Res. 43 (2009) 2409-2418.

[35] Y. Yang, Y. Chun, G. Sheng, M. Huang, pH-Dependence of pesticide adsorption by wheat-residue-derived black carbon, Langmuir 20 (2004) 67366741.

[36] M.V. López-Ramón, M.A. Fontecha-Cámara, M.A. Álvarez-Merino, C. MorenoCastilla, Removal of diuron and amitrole from water under static and dynamic conditions using activated carbons in form of fibers, cloth, and grains, Water Res. 41 (2007) 2865-2870.

[37] J. Peng, X.X. Qu, G.S. Wei, J.Q. Li, J.L. Qiao, The cutting of MWCNT using gamma radiation in the presence of dilute sulfuric acid, Carbon 42 (2004) 27352777.

[38] S.D. Kim, J.W. Kim, J.S. Im, Y.H. Kim, Y.S. Lee, Oxidation of multiwalled carbon nanotubes by nitric acid, J. Fluorine Chem. 128 (2007) 60-64.

[39] R.V. Hull, L. Li, Y. Xing, C.C. Chusuei, Pt nanoparticle binding on functionalized multiwalled carbon nanotubes, Chem. Mater. 18 (2006) 1780-1788.

[40] D. Lin-Vien, N.B. Colthup, W.G. Fateley, J.G. Grasselli, Infrared and Raman Characteristic Frequencies of Organic Molecules, Academic Press, London, 1991.

[41] D.G. Strawn, D.L. Sparks, The use of XAFS to distinguish between inner- and outer-sphere lead adsorption complexes on montmorillonite, J. Colloid Interface Sci. 216 (1999) 257-269.

[42] A.L. Roe, F. Kim, J. Hayes, C. Chisholm-Brause, G.E. Brown Jr., G.A. Parks, K.O. Hodgson, J.O. Leckiel, In situ X-ray absorption study of lead ion surface complexes at the goethite-water interface, Langmuir 7 (1991) 367-373.

[43] L. Dupont, E. Guillon, J. Bouanda, J. Dumonceau, M. Aplincourt, EXAFS and XANES studies of retention of copper and lead by a lignocellulosic biomaterial, Environ. Sci. Technol. 36 (2002) 5062-5066. 